\title{
RTV Automatic Spraying Equipment Research of Post Insulators
}

\author{
CHEN Jie, ZHU Mengzhou, LIANG Wei, ZHOU Zhicheng
}

State Grid Jiangsu Electric Power Company Research Institute, Nanjing, 211100;

15105161377@163.com

Keywords: RTV; external insulation; artificial spraying; automatic spraying

Abstract. RTV is one of effective methods of power transmission equipment external insulation properties improving. However, the performance of RTV coating was affected by spraying operation, which was mainly artificial spraying on site. In this paper, automatic spraying equipment was developed to deal with the uneven coating thickness, flow and other phenomena of artificial spraying. The device implemented the circumference of the spraying gun, up and down, swinging three-dimensional motion by setting the gun running posture parameters. It could be found out that the automatic spraying equipment highly improved the RTV coating quality and efficiency.

\section{Introduction}

RTV coating is perennial exposed outdoors perennially, suffering from the erosion of the sun, rain, heat and cold and inclement weather conditions, ultraviolet light, and the strong electromagnetic field. RTV spraying construction technology has a direct impact on the late operation performance. If the spraying construction is not standardized, making the product aging, retirement and retired, thereby affecting the performance and service life of RTV, resulting in huge economic losses.

In view of the phenomenon that the thickness of the coating is not uniform and flowing, the automatic spraying device is developed, which can improve the quality of spraying and spraying efficiency.

\section{Automatic Spraying Equipment Designing}

Automatic spraying equipment is developed to improve the quality and efficiency of RTV coating, reducing the impact on the process of spraying of human factors, accident rate, and diffusion of RTV, so it need to design an equipment that can complete the work of automatic spraying.

\section{Design Scheme}

The field factory automatic spraying equipment, such as Figure 1 shows, including the automatic balancing mechanism, multi section lifting mechanism and spraying executing part, paint and gas supply system, etc.

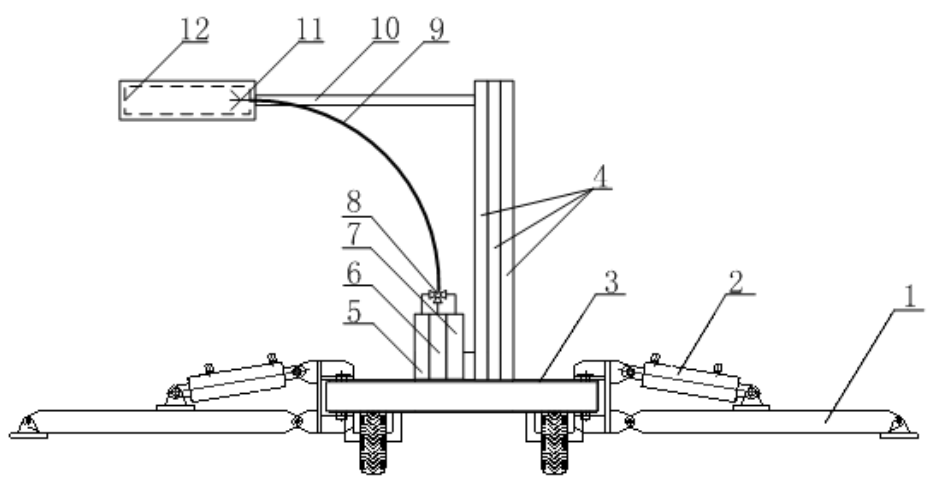

1. Supporting mechanism, 2. Hydraulic cylinder, 3. Chassis frame, 4. The lifting unit, 5. Compressed gas storage tank, a 6. Antifouling flashover coating storage tank, 7. Pure water storage tank, 8 . Through solenoid valve, 9 . Thoroughfare transmission pipe, 10. Cross bar, 11. Multi use spray gun, 12. Spray gun auxiliary motion mechanism

Fig 1 Schematic diagram of the structure of the automatic spraying equipment in the field.

As shown in the figure above, the automatic balancing mechanism comprises a supporting mechanism, a hydraulic cylinder and a chassis frame, and the four corners of the chassis frame are 
respectively hinged with a hydraulic cylinder with four groups of supporting mechanisms, and the whole device is kept stable by adjusting the supporting mechanism. Multi section lifting mechanism includes 3 lifting units, and the multi section lifting mechanism is pneumatic.

\section{Automatic Balancing Mechanism}

Automatic balance device structure schematic diagram as shown in Figure 2, includes supporting mechanism 1 , hydraulic cylinder 2 , chassis frame 3 , tilt sensor 4 , hydraulic station 5 , the control electromagnetic valve 6 , roller 7 , anti-slip mats 8 . The four corners of the chassis frame are hinged with one end of the supporting mechanism. One end of the hydraulic cylinder is hinged with the chassis frame, and the other end is hinged with the supporting mechanism. The upper part of the chassis frame is fixed with a hydraulic station, a control solenoid valve, an angle sensor, and a hydraulic station is fixed on the chassis frame to drive the expansion of hydraulic cylinder. Control solenoid valve is installed in the chassis frame of the hydraulic station, for controlling the four sets of hydraulic cylinder. Angle sensor is used in real-time detection of chassis tilt angle. The hydraulic cylinder is provided with a stroke sensor.

The hydraulic cylinder is a precision component with stroke sensor, the angle of the chassis frame is detected by the body angle sensor, and the signal is transmitted to the control system. Control system commands the solenoid valve, in order to control the expansion of the four sets of hydraulic cylinder, to achieve the automatic level control of chassis frame. Through the implementation of this device, the level of the whole equipment can be guaranteed effectively.

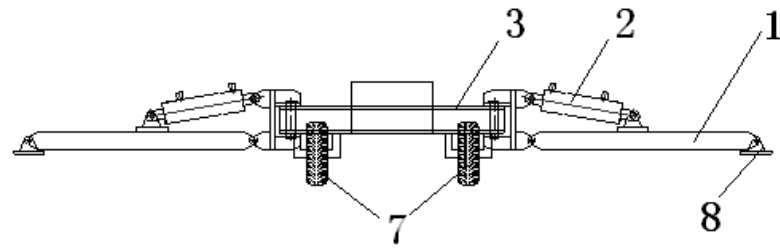

(a)

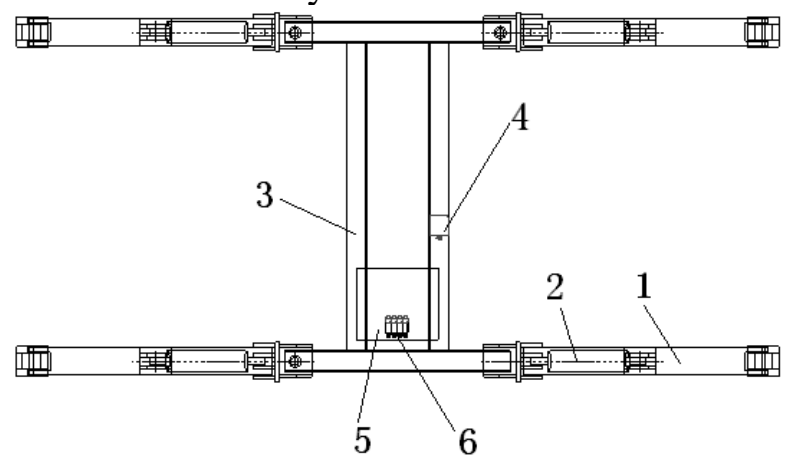

(b)

1. Supporting mechanism, 2.Hydraulic cylinder, 3. Chassis frame, 4. Tilt sensor, 5. Hydraulic station, 6. Control solenoid valve, 7. Roller, 8. Non slip mats

Figure 2 Field factory automatic spraying equipment structure diagram

The diameter of the $220 \mathrm{kV}$ substation insulator is $300 \mathrm{~mm}$, the single section height is $1700 \mathrm{~mm}$, the total height is about 7 meters to 8 meters, and considering the concrete supporting base, so the size of the equipment and the balance is designed around this size. In order that multi section $\mathrm{Z}$ axis upgrade supporting frame can work stably in the speed $30 \mathrm{~m} / \mathrm{s}$ wind (under 5 class but does not contain 5 class), the platform level of a solid structure is designed into the star type that can compensate the stability problem of the small size car, and the small size of the car is propitious to transport and move to the post insulators. The car is kept the safe distance of $400 \mathrm{~mm}$ to the $500 \mathrm{~mm}$ from the post insulator.

\section{Multi Section Lifting Mechanism}

Multi section lifting mechanism is designed to use the aluminum alloy material, so as to be able to find the balance between strength and weight. According to the diameter, height and other parameters of $220 \mathrm{KV}$ porcelain post insulator, the height can be raised to 8 meters, because of the adjustment of the fixed platform can reach the height of 9 meters, which can meet the height of the porcelain post insulator string.

The lifting mechanism is equipped with a precise position shift sensor, and the top is equipped with a contact switch which is directly linked to an emergency stop, so the upgrade mechanism is provided with a plurality of protection control procedures. 
The total weight of the lifting mechanism is about $300 \mathrm{~kg}$, and the lifting power supply is driven by a hydraulic pump driven by a power of $0.8 \mathrm{~kW}$, which is executed by a multi section telescopic hydraulic cylinder.
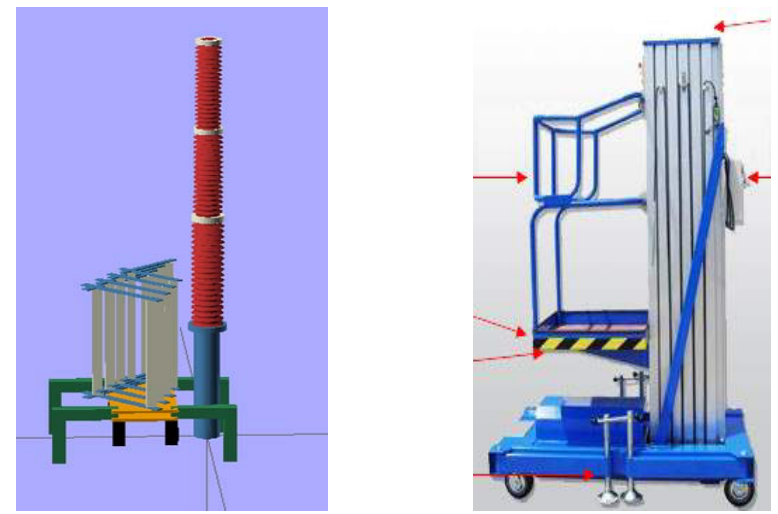

Fig. 3 Schematic diagram of multi section lifting mechanism

\section{Spraying Execution Mechanism}

Spraying execution mechanism schematic diagram as shown in Figure 4, including ring shaped track 1 , car 2 , planetary gear 3 , pneumatic motor 4 , guide wheel 5 , spray gun rack 6 , sliding guide unit 7, spray gun rack 8, spray gun swing cylinder 9, spray gun swing mechanism 10, spray gun 11. Circular track and trolley is matched through the planetary gear, rotating along the orbit of the outer meshing circumferential driven by the gas motor. By means of the effective coordination of all components in the device, it can move scale, fast and evenly around the circumference of the whole insulator, upper and lower, so as to realize the factory spraying of the insulator, improve the quality of spraying.

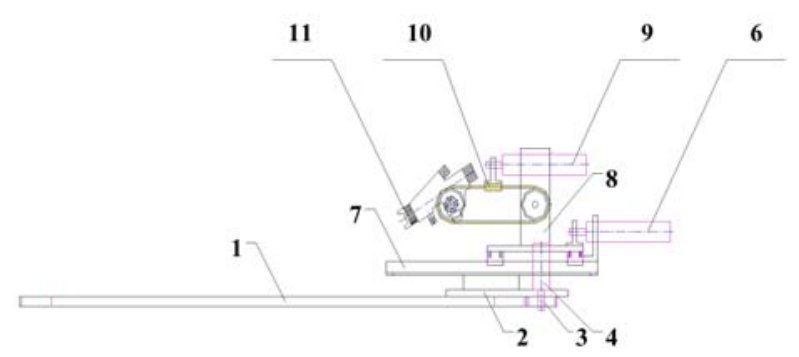

(a)

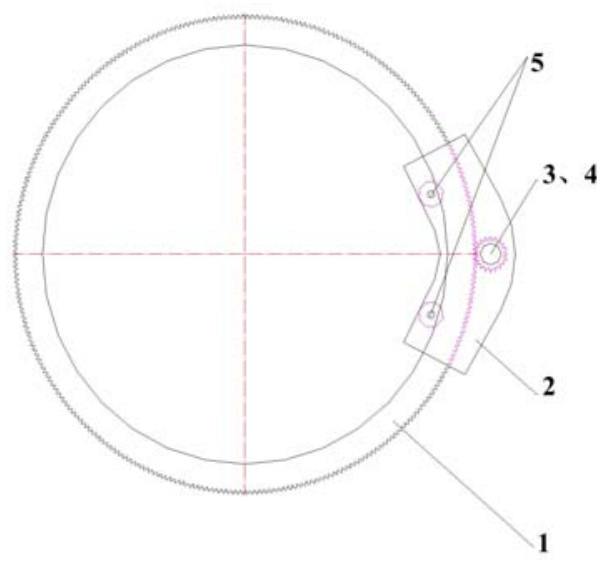

(b)

1 ring shaped track, 2 car, 3 planetary gear, 4 pneumatic motor, 5 guide wheel, 6 gun rack moving cylinder, 7 slide rail unit, 8 gun rack, 9 gun oscillating cylinder, 10 gun swing mechanism, 11 gun.

Fig. 4 Schematic diagram of the structure of the spray execution mechanism

\section{Spraying Gun Circumferential Movement}

The circular movement of the spray gun is mainly composed of a circular ring guide rail and a car. The outer side of the circular ring is arranged as a gear structure, a car is arranged on the track. The planetary gear is connected to the outer side of the circular ring, and the planetary gear is driven by a pneumatic motor to rotate the outer side of the track. The bottom of the car has a guide wheel, the guide wheel id connected with the inner side of the slide. 


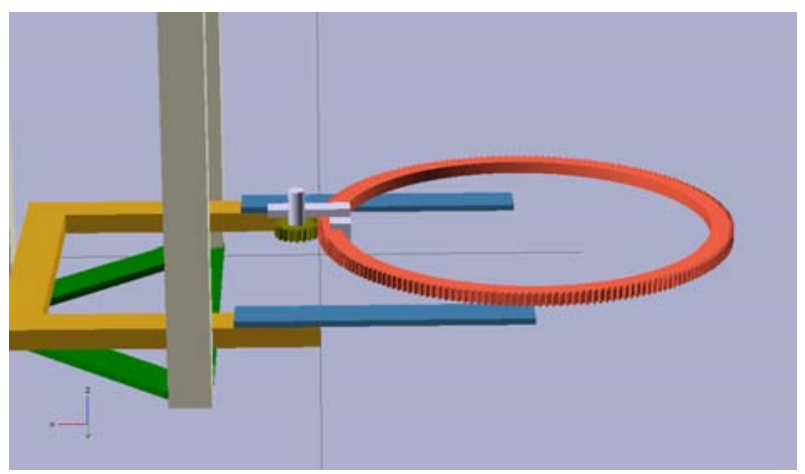

Fig. 5 Schematic diagram of circular ring

The schematic diagram of the circular guide rail is shown in Figure 5. Circular guide rail takes the semicircle design, the assembly is fast, and after the assembly it can do the reciprocation of 360 degree, which can guarantee the stability of the whole system, and fast movement around the circular path.

At the top of the arc guide rail, there is a light circle arc guide rail, ensure the cable, air pressure pipe, coating tubes can move along the circular arc gear following the motor. When reverse movement, the circular arc guide rail towline composed of multi section chain can automatic fold, along a circular arc guide rail orderly.

The diameter of the motion guide gear is $1000 \mathrm{~mm}$, the size of the other bodies are calculated according to this size, the diameter of the spray gun is $800 \mathrm{~mm}$, which can be compatible with some larger device.

\section{Seesaw Movement of Gun}

In order to spray the porcelain post insulator umbrella piece side and deep umbrella piece spacing, just adjusting the angle of the spray gun is not enough, it must be able to do precise movement on $\mathrm{Z}$ axis, to achieve the gun's seesaw movement. So it can be accurate positioned, and can do reciprocating movement quickly on $\mathrm{Z}$ axis, so the paint will be evenly spread to the umbrella piece space and the bottom of the umbrella, to solve the problem of leakage.

The movement of the spray gun is mainly performed by the vehicle and the slide rail unit. A slide rail unit is arranged on the trolley, and the slide rail is connected with the upper part of the trolley, and the upper part of the slide rail unit is connected with the spray gun holder, and the outer side is connected with the spray gun holder. Moving the cylinder with a gun rack, the gun holder moves along the slide rail unit.

Fast moving mechanism is made of aluminum alloy support frame and packaging. Equipped with sensors, ultrasonic ranging sensor and other protective mechanisms to ensure the equipment can complete the expansion of the task safely, efficiently and accurately. Motion mechanism is made of high precision motion system, such as guide, ball screw and so on, has been designed with the full enclosed shielding enclosure, which can prevent the equipment from the coating fog adhering, reduce the maintenance frequency and the failure rate. The adjustment range of the mobile mechanism is $800 \mathrm{~mm}$.

\section{Spray Gun Up and Down}

In order to be able to spray the narrow gap of the umbrella and the bottom of the umbrella, a swinging joint is installed, which can do the rotation up and down and high speed reciprocating motion. The swing movement of spray gun depends on the swing cylinder and the oscillating mechanism. The spray gun holder is provided with a spray gun and a swing mechanism is connected with the lance. The inner side of the gun is connected with the lance, and the swing of the cylinder is driven by a gun. This allows spraying fan to cover the downside of insulators, solving the fundamental problem in the spraying quality. 


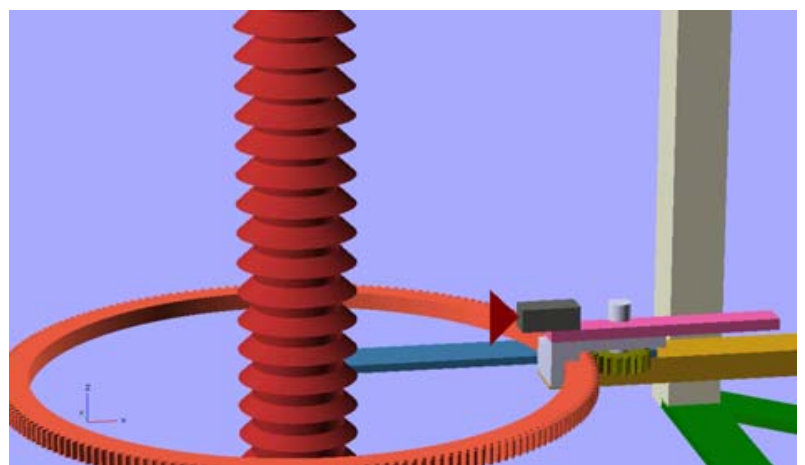

Fig. 6 the three-dimensional structure diagram of the spray execution mechanism

\section{Other Accessories}

\section{Anti-spray diffusion protective cover}

The spray diffusion protective cover is mainly used to reduce the spray diffusion in the process of spray coating, which is beneficial to the environment. In the process of design, it is not only able to prevent the spray particles from spreading, but also can be able to resist the wind at the speed of $30 \mathrm{~m} / \mathrm{s}$ (under 5 class but does not contain 5 class). Taking the shrimp cage structure, we make a protective cover with the diameter of $1200 \mathrm{~mm}$ by steel wire, and use micro hole filter cloth of 100 mesh (149 microns, about $0.15 \mathrm{~mm}$ ) in the periphery of wire supporting frame. Made of nylon or other synthetic materials, quality can be neglected, so the coatings fog can be kept out by the filter cloth occlusion, but the air can pass through, reducing the wind effect on the equipment.

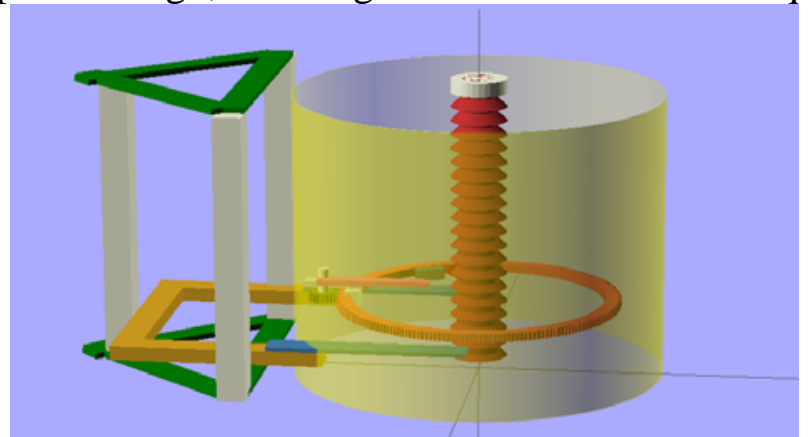

Fig. 7 the three-dimensional structure of the spray diffusion protective cover

\section{Spray System}

Spray system contains the pressure filter, solenoid valve, spray gun, etc.

Pressure filter controls the pressure of $3 \mathrm{~kg} / \mathrm{cm} 2$, and each of the pressure filter is controlled in the highest pressure of $3 \mathrm{~kg} / \mathrm{cm} 2$, and if the pressure of the paint bucket is more than $4 \mathrm{~kg} / \mathrm{cm} 2$, the safety valve will start to exhaust decompression automatically.

The solenoid valve is controlled by the program to meet the needs of the spraying process. When the fault comes out it can be closed manually, in the distribution cabinet there is a manual solenoid valve switch.

Spray gun is automatic, including 4 entrances and one exit. The entrance is composed of a paint inlet, an atomizing pressure inlet, an injection pressure inlet and an auxiliary air pressure inlet. By adjusting the rear thimble screw valve, the flow of the paint could be controlled.

\section{Field Debugging}

After commissioning of the automatic spraying equipment components, the debug testting was done in Jiangsu Electric Power Research Institute. 


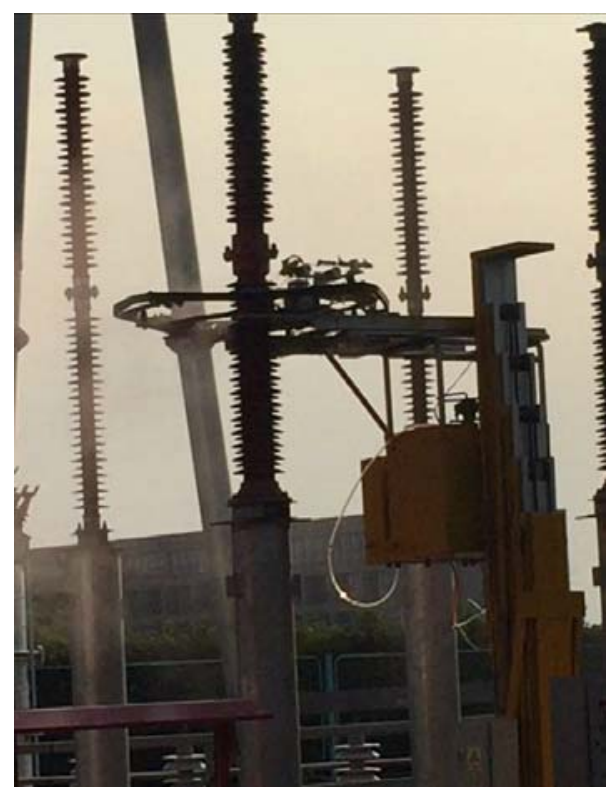

Figure 8 automatic spraying equipment scene machine debug screen

After debugging, the whole machine completes the automatic coating of the $220 \mathrm{kV}$ pillar insulator, achieving the design requirements.

After the field commissioning, comparing the automatic spraying and manual spraying, the advantages are shown in Table 1.

Table 1 Advantages of Automatic Spraying and Manual Spraying

\begin{tabular}{|l|l|l|}
\hline Contrast project & Manual spraying & Automatic spraying \\
\hline Spraying quality & $\begin{array}{l}\text { Depend on the experience of the } \\
\text { workers, can't guarantee the } \\
\text { uniformity of spraying thickness }\end{array}$ & $\begin{array}{l}\text { Setting automatic program, which } \\
\text { can effectively guarantee the } \\
\text { uniformity of spray thickness }\end{array}$ \\
\hline Spraying efficiency & $\begin{array}{l}\text { About 15 minutes to spray a 220kV } \\
\text { post insulator }\end{array}$ & $\begin{array}{l}\text { About 8 minutes to spray a 220kV } \\
\text { post insulator }\end{array}$ \\
\hline Security & $\begin{array}{l}\text { Spraying workers need to climb up the } \\
\text { scaffolding, or take the lift car, there } \\
\text { are security risks }\end{array}$ & $\begin{array}{l}\text { Operator set up the parameters to } \\
\text { spray on the ground, there is no } \\
\text { high operating risk }\end{array}$ \\
\hline Environmental impact & $\begin{array}{l}\text { In the process the spraying paint drift a } \\
\text { lot, effect the substation and the } \\
\text { surrounding environment }\end{array}$ & $\begin{array}{l}\text { Set up a spray diffusion protective } \\
\text { cover, reduce spray pollution } \\
\text { effectively }\end{array}$ \\
\hline
\end{tabular}

\section{Conclusions}

1) Field spraying mainly uses the manual spraying, and the running performance of RTV is directly influenced by the operation experience of the workers and the spray process. Through the acceptance test of RTV coating, find that the thickness of the coating is not uniform.

2) Develop an automatic spraying device, which is suitable for the post insulator. By setting up the running position of spray gun, the spray gun can realize the circumference, upper and bottom, and the three-dimensional motion.

3) After spraying, it could be found out that the automatic spraying equipment can improve the quality and efficiency of RTV spraying effectively.

\section{References}

[1] DL/T 627-2012 Room temperature vulcanized silicon rubber anti-pollution coating for insulators 
[2] WU Guangya, CHEN Yuan, ZHANG Shengcai, et al. Application and prospect on RTV of solidified silicon rubber in normal temperature for insulator[J], Electrical Equipment, 2007, vol.8, no.10, pp 22-26.

[3] Guan Zhicheng, Liu Yingyan, Zhou Yuanxiang, et al. Insulators and outdoor insulation of power transmission equipments[M]. Bei'jing: Tsinghua University Press, 2006.

[4] TU Youping, CHEN Jinging, XU Zhuo, et al. Uneven Change Characteristic of Composite Insulators Hydrophobicity in Long-time Service [J]. High Voltage Engineering, 2013, 39(06): 1469-1475.

[5] SU Zhi-yi, CHEN Gang, LI Qing-feng, et al. Study on Aging and Criterion of Sheds and Housing of Silicon Rubber Composite Insulator [J]. Power System Technology, 2006, 30(12): 53-57. 